\title{
Gasoline Prices, State Gasoline Excise Taxes, And The Size Of Urban Areas
}

James M. McGibany (E-mail: james.mcgibany@marquette.edu), Marquette University

\begin{abstract}
A monocentric model of land use that assumes urban spatial size is determined by a set of exogenous variables is employed to test the hypothesis that urban land size is negatively related to gasoline prices. Using a model from Brueckner and Fansler (1983), the amount of urbanized land area is shown to be a function of population, income, agricultural land prices and commuting costs. The latter is measured as the price of gasoline, broken into two components; the amount of any state gasoline excise tax imposed plus the total price paid by consumers minus such a tax. Using 1990 data, an empirical model that defines the dependent variable as the average-sized urban area in each state is estimated. The results confirm that higher levels of population and income contribute to larger amounts of urbanized land area, while higher land prices are primarily associated with smaller urban size. Of importance to this study, the results indicate that states with higher gas prices, mainly due to increased state gasoline excise taxes, are associated with smaller urban size.
\end{abstract}

\section{Introduction}

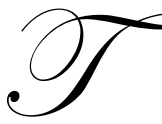

he rapid spatial expansion of urban areas, popularly referred to as urban sprawl, has been analyzed extensively. One facet of the research is simply to document the magnitude of the problem. For example, since 1980, suburban population has grown by approximately ten times faster than populations in central cities. This push to the suburbs even as central city population lags is a major reason why land for urban use surrounding large metropolitan areas has expanded twice as fast as the overall urban population. A second aspect of the research has focused on the development of cities in an attempt to ascertain historical growth patterns. In this vein of research, one often examines the locational advantages of cities (i.e., proximity to waterways) that allowed them to expand due to high level of commercial activity that spawned jobs and attracted people. An important part of the research in this area analyzes the costs and consequences of urban sprawl on society. This includes issues regarding increased commute times, higher levels of air and water pollution, and the loss of farmlands and wetlands, all of which can be considered increases in negative externalities or loss of amenities that are related to urban sprawl. Of course, such research has spawned further studies and debates in an attempt to develop policies designed to slow the conversion of land at the fringe of cities to urban use.

At the heart of the debate regarding such policies is the determination of whether markets are able to allocate land use efficiently. One might suggest that a less than efficient allocation can lead to less than optimal densities and increasing amounts of urban sprawl (Ohls and Pines, 1975; Peiser 1989, 1990; Breslaw, 1990). An economist=s view of the issue stems from our use of analytical models that try to show that various phenomenon, such as urban spatial size, can be analyzed as part of an orderly market process. This inquiry follows that line of research (Muth, 1969; Mills, 1972; and Wheaton, 1974) by assuming that urban spatial size can be determined by a set of exogenous variables. Specifically, the model used here builds upon the work of Brueckner and Fansler (1983) which showed that urbanized land area is determined by factors such as population, income, agricultural land prices near urban areas and variables that represent commuting costs. In particular, they showed that for medium-sized metropolitan areas, higher income and population tend to increase the size of the urban area, all else fixed. On the other hand, all else fixed, higher land prices at the edge of the urban area and higher commuting costs tended to be associated with smaller measured urban areas. 
This research focuses on one particular commuting cost, the price of gasoline. Given that fuel costs are an important part of overall commuting costs, the plan of the paper is to ascertain the extent to which gasoline prices can help explain the variation in the amount of land in urbanized areas. Because the final price of gasoline to consumers can include a significant amount of state excise taxes, depending on the state, the analysis uses two measures of the price of gasoline (the total price as well as the price broken into its state excise tax and retail components) for this purpose. The results confirm the findings of Brueckner and Fansler (1983) in that higher levels of population and income in the region contribute to larger amounts of urbanized land areas, while increased agricultural land prices are primarily associated with smaller amounts of urban land area. With respect to the focus of this paper, the results indicate that states with higher gas prices, mainly due to higher state excise taxes, are associated with reduced amounts of urbanized land area.

The remainder of the paper can be outlined as follows. The next section offers a brief review of the research on urban spatial size and discusses the theoretical model. The empirical model is specified in the following section, along with a discussion of the data. The empirical results are reported in fourth section, while the final sections offer concluding remarks and suggestions for future research.

\section{Background}

One of the leading models of urban structure or urban land use is the monocentric model attributed to Muth (1969) and Mills (1972). ${ }^{1}$ That model postulates that firms choose a location for production under conventional assumptions regarding profit-maximization. For example, it is assumed that firms need to ship their goods after production (and receive input from other areas), and the transportation hub is assumed to be located near the center of the urban area. All else the same, having the production facility near the shipping point will increase profits. Analogously, households are assumed to maximize satisfaction by choosing the location of their residence (as a part of choosing the type and quantity of other goods and services). Household income is earned in the course of working at the afore-mentioned firms, so they will need to commute to the businesses, that is, to the urban center. All else the same, just as firms wish to be near the transportation hub to maximize profits, households (commuters) will wish to minimize commute time to maximize satisfaction.

Using that as a basis, Brueckner and Fansler (1983) develop a model that tries to explain the size of urban areas. ${ }^{2}$ The assumptions used to achieve their theoretical model are: all consumers earn equal income and have similar preferences regarding housing and all other goods; housing is measured in square feet of floor space, and the rental price per square foot is a declining function of the distance to the urban center; households, no matter where they locate in the area, maximize their utility over housing and all other goods subject to an income constraint that shows the sum of all other goods and housing purchased must equal their income minus the cost of commuting to and from the urban center; and housing is competitively produced with a constant returns to scale production function using capital and land.

The assumptions that consumers have similar preferences and equal incomes, allows households to reach the same utility level even though they live in different locations due to the spatial variation in the rental price of housing. Simple utility-maximization reveals that housing and its rental price are functions of income, commuting costs and urban size (distance to the urban center). On the other hand, housing suppliers maximize profits per acre of land as the revenue generated from providing a certain amount of housing minus the land rent and capital costs needed to construct that housing. Given the rental price of housing (a component of this revenue) is determined from the utility-maximizing conditions, the profit-maximizing conditions show that the amount of capital per unit of land and the rental price of land are also functions of income, commuting costs and urban size. ${ }^{3}$

The utility and profit maximizing conditions are then used to solve for the equilibrium conditions for the urban area in terms of land rent at the urban fringe and urban population. Both of these variables are found to be functions of income, commuting costs and the size of the urban area (the distance from urban center to the urban-rural boundary). For a given urban population, ${ }^{4}$ one can simultaneously employ the equations that describe the urban fringe land rent and urban population to equate the demand and supply of housing in the area. 
Originally, Muth (1969) and Mills (1972) used these equations to derive the comparative static properties for housing, though Wheaton (1974) showed that this specification could also be used to show the comparative static results for land usage in the urban area. In particular, the equations can show the expected marginal impacts on urban area size from changes in population, income, land prices and commuting costs. Holding all else fixed, as population or income increases, the size of the urban area is expected to increase, while higher land prices at the urban fringe and higher commuting costs will tend to decrease urban size. These results are quite straightforward; for example, an increase in income will elevate housing demand that will tend to increase the size of the city. Similarly, more population will require more urban space to house the larger number of households that is likely to occur. Both of these impacts are due to the increase in the production of new housing that will be a reaction to the higher housing demand. Among other things, this will tend to increase the price of land in the area and at the urban fringe. Some land is converted from rural to urban use, increasing the size of the urban area. An analogous reaction regarding the city size will occur if commuting costs or urban land prices fall.

\section{Empirical Model And Data Definitions}

The model implied in the previous section is tested with an empirical counterpart initially specified in linear form for simplicity:

$\mathrm{SIZE}=\beta_{0}+\beta_{1} \mathrm{~N}+\beta_{2} \mathrm{Y}+\beta_{3} \mathrm{R}+\beta_{4} \mathrm{c}+\mathrm{e}_{1}$

The dependent variable is a measure of the size of the urban area (SIZE), and the independent variables are population $(\mathrm{N})$, income $(\mathrm{Y})$, land prices (rent) at the urban fringe $(\mathrm{R})$, and commuting costs $(\mathrm{c})$.

The data used to for the empirical investigation is mainly from the 1990 Census. ${ }^{5}$ The size of the urban area (SIZE) is the Aurbanized areas@ definition that has been used since the 1950 Census, and mirrors the dependent variable used by Brueckner and Fansler (1983). That study used data from the 1970 Census on urbanized areas for 40 selected small to medium-sized metropolitan areas. ${ }^{6}$ In this study, the dependent variable is the sum of land in all of the urbanized areas in each state divided by the number of urbanized areas in the state. Essentially, the dependent variable is the average size, in square miles, of urbanized areas in the state. ${ }^{7}$ Population (URBPOP) is defined as the population of the state that resides inside urbanized areas. Income (INCPCAP) is taken to be the statewide personal income per capita. Land prices at the urban fringe (LANDP) are approximated by the price of agricultural land per acre in the state.

The focus of this study is on the commuting cost variable (c). Brueckner and Fansler (1983) approximated this impact using one of two variables, the percentage of commuters using public transit and the percentage of households owning automobiles. High values of the former suggest high commuting costs, thus should be negatively related to city size, while high values of the second suggest low commuting costs and larger urbanized areas. However, neither variable was found to have a significant impact on the size of urbanized areas in their study. For comparison, this study will include the percentage of commuters using public transit (TRANSIT) in a specification of the model. The main focus of this study is to examine the price of gasoline and the components of that price (the price of gasoline not including state excise taxes plus the amount of excise taxes on gasoline imposed by the state) as alternative measures of commuting costs. The price of gasoline less state tax (PGSLSTX) plus the state excise tax on gasoline (GASTX) sums to the total retail price for gasoline in each state (PGASTOT). Variable names, definitions, summary statistics and sources are found in Table 1.

The dependent variable, the average-sized urban area in the state, ranges from a high of 337.8 square miles (Arizona, given the large size of the Phoenix metropolitan area) to a low of 29.34 square miles (West Virginia). The mean of the dependent variable is just over 120 square miles, which, for point of reference, is slightly more than double the size of the urban area contained in the Burlington, Vermont metropolitan area, or just under the size of the urbanized land area in the Anchorage, Alaska metropolitan area. Further, one can note that both the retail price of gasoline before state excise taxes and the amount of state excises taxes paid vary noticeably across states. Finally, state excise taxes on gasoline averaged just under $18 \%$ of the total price of gasoline paid by consumers in 1990. 
Table 1

Variable Name, Definition, Source, Predicted Sign And Summary Statistics

\begin{tabular}{|c|c|c|c|c|c|c|}
\hline $\begin{array}{l}\text { Variable } \\
\text { Name }\end{array}$ & $\begin{array}{l}\text { Variable Definition and } \\
\text { Source }\end{array}$ & $\begin{array}{l}\text { Expected } \\
\text { Sign }\end{array}$ & Mean & Maximum & Minimum & $\begin{array}{l}\text { Standard } \\
\text { Deviation }\end{array}$ \\
\hline SIZE & $\begin{array}{l}\text { The sum of land in urbanized areas in the state divided by the number of } \\
\text { urbanized areas in the state, in square miles, } 1990.1990 \text { Census }\end{array}$ & $\begin{array}{l}\text { Dependent } \\
\text { Variable }\end{array}$ & 120.27 & 337.80 & 29.34 & 66.49 \\
\hline URBPOP & $\begin{array}{l}\text { State population inside of urbanized areas, in thousands, } 1990.1990 \text { Cen- } \\
\text { sus }\end{array}$ & + & 3153.04 & 25466.13 & 87.09 & 4474.5 \\
\hline INCPCAP & $\begin{array}{l}\text { State personal income per capita, in thousands of \$, } 1990 . \\
\text { Bureau of Economic Analysis }\end{array}$ & + & 13.65 & 20.19 & 9.65 & 2.34 \\
\hline LANDP & $\begin{array}{l}\text { Statewide average value of land and buildings, per acre, in \$, 1990. US } \\
\text { Dept. of Agriculture, Economic Research Service }\end{array}$ & - & 1219.2 & 5028.0 & 149.0 & 1128.5 \\
\hline LANDP^2 $^{\wedge}$ & Square of LANDP & + & & & & \\
\hline TRANSIT & $\begin{array}{l}\text { Percentage of commuters in the state using public transportation, \%, } 1990 . \\
1990 \text { Census }\end{array}$ & - & 3.11 & 24.8 & 0.3 & 3.92 \\
\hline PGASTOT & $\begin{array}{l}\text { Per gallon price of gasoline, in cents. This is the average price of all blends } \\
\text { plus the state gasoline excise tax, } 1990 . \\
\text { US Energy Information Administration and Census of State Government } \\
\text { Tax Collections }\end{array}$ & - & 95.37 & 109.0 & 82.1 & 5.96 \\
\hline GASTX90 & $\begin{array}{l}\text { State gasoline excise tax, in cents, } 1990 . \\
\text { US Energy Information Administration }\end{array}$ & - & 16.67 & 22.0 & 7.50 & 3.81 \\
\hline PGSLSTX & PGTOT - GASTX90 & - & 78.70 & 101.0 & 69.7 & 6.05 \\
\hline GASTX86 & $\begin{array}{l}\text { State gasoline excise tax, in cents, } 1986 . \\
\text { US Energy Information Administration }\end{array}$ & & 13.92 & 20.0 & 4.0 & 3.60 \\
\hline DGASTX & GASTX90 - GASTX86 & - & 2.75 & 9.85 & 0.0 & 2.49 \\
\hline
\end{tabular}




\section{Results}

While the theory suggests the marginal impacts of the various influences on city size, it does not give any insight as to the functional form of the empirical model. All variables are converted to natural logs with the exception of the percentage of commuters using public transit, the price of gasoline and its components, and the average size of urban areas in the state. The first is due to the fact that the variable is defined in percentage terms, while the latter two are strictly for ease in interpretation. The last pair of assumptions allows one to show how a one cent increase in the price of gasoline (or its components) will change the number of square miles in the average urbanized area of each state.

Given the theory of the previous section and the above assumptions, the empirical model is first specified as

SIZE $=\beta_{0}+\beta_{1} \ln ($ URBPOP $)+\beta_{2} \ln ($ INCPCAP $)+\beta_{3} \ln ($ LANDP $)+\beta_{4}$ PGASTOT $+\beta_{5}$ TRANSIT $+\mathrm{e}_{2}$

The results of this model are shown in the first column of data in Table 2. Given the cross section nature of the data, the model (as well as all subsequent specifications) is estimated using the generalized least squares method of White (1980) to correct standard errors and the corresponding t-statistics for potential heteroskedasticity. All variables have estimated coefficients anticipated by theory, but only the population and income variables are statistically significant at traditional significance levels. Since the specific functional form of the test equation is unknown, a regression specification error or RESET test attributable to Ramsey (1969) is performed. The results of that test, shown in Table 3, suggest that one cannot reject the null hypothesis; therefore, the current specification is adequate. Both linear and $\log$-linear counterparts to Equation (2) were estimated, and the results are generally consistent with those reported above. ${ }^{8}$

Table 2.

Regression Estimates For Equations (2) - (5)

Dependent Variable $=$ SIZE

(Absolute value of $\mathrm{t}$-statistic in parentheses) $^{\mathrm{b}}$

\begin{tabular}{|c|c|c|c|c|c|}
\hline Variable & EQ. (2) & EQ. (3) & EQ. (4) & EQ. (4a) & EQ. (5) \\
\hline $\ln ($ URBPOP) & $\begin{array}{l}30.53 * \\
(2.98) \\
\end{array}$ & $\begin{array}{l}31.48 * \\
(3.93)\end{array}$ & $\begin{array}{l}34.45 * \\
(3.78) \\
\end{array}$ & $\begin{array}{l}33.05 * \\
(6.08)\end{array}$ & $\begin{array}{l}33.80 * \\
(6.01)\end{array}$ \\
\hline $\ln ($ INCPCAP) & $\begin{array}{r}144.3 * \\
(2.77)\end{array}$ & $\begin{array}{r}136.8 * \\
(3.17)\end{array}$ & $\begin{array}{l}99.16 * * \\
(2.42)\end{array}$ & $\begin{array}{c}108.7 * * \\
(2.56)\end{array}$ & $\begin{array}{r}114.5 * \\
(2.70)\end{array}$ \\
\hline $\ln ($ LANDP) & $\begin{array}{c}-24.26 \\
(1.46)\end{array}$ & & & & \\
\hline LANDP & & $\begin{array}{l}-0.070 * * \\
(2.19)\end{array}$ & $\begin{array}{l}-0.077 * * \\
(2.46)\end{array}$ & $\begin{array}{l}-0.072 * * \\
(2.53)\end{array}$ & $\begin{array}{l}-0.070 * * \\
(2.53)\end{array}$ \\
\hline LANDP^$^{\wedge} 2$ & & $\begin{array}{l}0.12 \mathrm{E}-04 * * \\
(2.04)\end{array}$ & $\begin{array}{l}0.14 \mathrm{E}-04 * * \\
(2.47)\end{array}$ & $\begin{array}{l}0.13 \mathrm{E}-04 * * \\
(2.40)\end{array}$ & $\begin{array}{l}0.13 \mathrm{E}-04 * * \\
(2.33)\end{array}$ \\
\hline PGASTOT & $\begin{array}{l}-0.518 \\
(0.26)\end{array}$ & $\begin{array}{l}-0.400 \\
(0.23)\end{array}$ & & & \\
\hline PGSLSTX & & & $\begin{array}{r}0.685 \\
(0.40) \\
\end{array}$ & & \\
\hline GASTX90 & & & $\begin{array}{l}-3.458 * * \\
(1.75)\end{array}$ & $\begin{array}{l}-3.331 * * \\
(1.91)\end{array}$ & \\
\hline DGASTX & & & & & $\begin{array}{l}-4.692 * \\
(2.49)\end{array}$ \\
\hline TRANSIT & -0.708 & $(0.43)$ & & & \\
\hline Intercept & -261.7 & -374.9 & -337.4 & -295.8 & -360.9 \\
\hline adj. $R 2$ & 0.434 & 0.471 & 0.500 & 0.509 & 0.502 \\
\hline F-Statistic & $8.51 *$ & $9.74 *$ & $9.84 *$ & $11.14 *$ & $10.88 *$ \\
\hline DW statistic & 1.94 & 1.81 & 1.87 & 1.86 & 1.95 \\
\hline
\end{tabular}

a All equations are estimated using White's (1980) generalized least squares method which corrects the standard errors for potential heteroskedasticity.

b * or ** indicate the estimated coefficients or the test statistics are significantly different from zero at the $1 \%$ or $5 \%$ levels, respectively. Two-tailed tests are used for all variables except PGASTOT, GASTX90, PGSLSTX and DGASTX. 
Table 3.

Regression Specification Error (RESET) Tests For Equations (2) - (5)

Dependent Variable $=$ SIZE

\begin{tabular}{lcccc}
\hline EQ. (2) & EQ. (3) & EQ. (4) & EQ. (4a) & EQ. (5) \\
2.78 & 0.63 & 0.84 & 1.26 & 2.33 \\
\hline c & The square and cube of the fitted values are added to the respective \\
specifications and an auxiliary regression estimated. The above \\
are test statistics for the joint significance of these added variables. \\
The 10\% critical value for a Chi-Square with 2 degrees of free- \\
dom is 4.61.
\end{tabular}

Next, two minor changes to Equation (2) are explored. First, the square of LANDP (LANDP^2) is added to the model. This reflects the fact that in states where the majority of land is in urbanized areas, the remaining agriculture land prices are likely to be quite high. Therefore, in these states, higher land prices at the urban fringe would be associated with larger sized urban areas. To capture the potential non-linear impact such that higher land values are initially associated with smaller urban areas, but eventually larger urban areas are surrounded by high land values, LANDP^ 2 is added. Because of this change, LANDP and its square must enter the model in linear rather than logarithmic form, as the natural logarithms of a variable and its square are simple multiples of one another, which would introduce perfect multicollinearity to the empirical model. The second change is that since TRANSIT was shown to be insignificant in Equation (2) and in the results of Brueckner and Fansler (1983), that variable will no longer be considered in any further empirical specifications. These changes are shown by the equation:

$\mathrm{SIZE}=\beta_{0}+\beta_{1} \ln (\mathrm{URBPOP})+\beta_{2} \ln (\mathrm{INCPCAP})+\beta_{3} \mathrm{LANDP}+\beta_{4} \mathrm{LANDP}^{\wedge} 2+\beta_{5} \mathrm{PGASTOT}+\mathrm{e}_{3}$

The results of this revised specification are found in the second column of data in Table 2 and are quite similar to those of Equation (2). Specifically, income and population show a positive and statistically significant impact on the dependent variable, and while negative, gasoline prices are found to have a statistically insignificant impact on the size of urban areas. Of particular interest are the negative and positive estimated coefficients on LANDP and LANDP^2, that show the non-linear association between land prices and urban size. ${ }^{9}$ The RESET test results (Table 3 ) once again are such that the null hypothesis cannot be rejected, indicating that the current functional form is adequate.

The next change is to break the price of gasoline into two components: the amount of state gasoline excise taxes in 1990 (GASTX90) and the remainder of the retail price (PGSLSTX). This change is shown by the equation:

SIZE $=\beta_{0}+\beta_{1} \ln ($ URBPOP $)+\beta_{2} \ln ($ INCPCAP $)+\beta_{3}$ LANDP $+\beta_{4}$ LANDP $^{\wedge} 2+\beta_{5}$ PGSLSTX $+\beta_{6}$ GASTX90 $+\mathrm{e}_{4}$

The results of this specification are found in the third column of data in Table 2, while the RESET test results are reported in Table 3. The most important change between this set of results and those of previous specifications is that except for the gas price less state excise tax variable, coefficients of all remaining variables have the sign anticipated by theory and are all significant at the 5\% level of significance, including that for GASTX90 (using a one-tail test).

The fact that the market price of gasoline variable is not significant is unfortunate, but not fatal, as higher state gasoline taxes have the expected negative relationship with the average urban size. Regional variation in retail gasoline prices may simply be due to supply considerations, such as the distance from the state to the nearest refineries. While all states experience higher or lower prices as market conditions change, the impact of gasoline prices on urban size at one point in time may be clouded by these supply conditions. Given that the coefficient of the price of gasoline less state excise taxes is not significant (PLGSTX in Equation (4)), it is excluded and a revised regression is estimated. This change is shown by the equation:

$\mathrm{SIZE}=\beta_{0}+\beta_{1} \ln (\mathrm{URBPOP})+\beta_{2} \ln (\mathrm{INCPCAP})+\beta_{3} \mathrm{LANDP}+\beta_{4} \mathrm{LANDP}^{\wedge} 2+\beta_{5} \mathrm{GASTX} 90+\mathrm{e}_{4 \mathrm{~A}}$ 
The results, shown in the fourth column of data in Tables 2 and 3, now show all estimated coefficients to be significant (one-tail test for GASTX90) and of the anticipated theoretical sign. ${ }^{10}$ Further, the RESET results show this is an adequate functional form.

The fact that states with lower gasoline excise taxes tend to be associated with large-sized urban areas leads to an interesting policy implication. The result suggests that so-called urban sprawl can be reduced, all else constant, by the advent of higher gasoline excise taxes that help to increase commuting costs. ${ }^{11}$ The final empirical model aims to explore that proposition by revising the specification to incorporate the change in state gasoline excise taxes (DGASTX) over several years leading up to 1990. For purposes of this study, DGASTX is defined as the state gasoline excise tax in 1986 subtracted from the gasoline excise tax in $1990 .{ }^{12}$ For point of reference, thirty-nine states raised gasoline excise taxes over this period, thirty by at least 2 cents. Making this revision leads to the following equation:

$$
\text { SIZE }=\beta_{0}+\beta_{1} \ln (\mathrm{URBPOP})+\beta_{2} \ln (\mathrm{INCPCAP})+\beta_{3} \mathrm{LANDP}+\beta_{4} \mathrm{LANDP}^{\wedge} 2+\beta_{5} \mathrm{DGASTX}+\mathrm{e}_{5}
$$

The results for this specification are given in the last columns of data in Tables 2 and 3 . The estimated coefficients on population, income and land values are virtually unchanged from the proceeding specification, while that of DGASTX has the expected negative sign and is significantly different from zero. Specifically, the results show that where gasoline excise taxes were raised by 1 cent in the last half of the decade of the 1980s, urban areas averaged nearly 4.7 square miles smaller than in states that did not raise these taxes, all else fixed.

\section{Conclusion}

The monocentric model of urban land use, popularized by Muth (1969) and Mills (1972), is employed to examine the impacts of income, population, land prices at the urban fringe and commuting costs on the spatial size of cities, specifically the amount of land in urbanized areas within each state in 1990. This study confirms the findings of that model. In particular, higher levels of urban population and personal income per capita tend to be associated with more land in urbanized areas. On the other hand, state agricultural land prices show a non-linear relationship with the size of urbanized areas, as the impact on urban size from higher land prices decreases at a decreasing rate. However, the focus of the study is to assess the impact of gasoline prices on the size of urbanized areas. In a variety of specifications of a model similar to that of Brueckner and Fansler (1983), higher gasoline excise taxes (a component of overall gas prices) are associated with smaller-sized urbanized areas.

This result suggests that policymakers may be able to reduce the growth of urban sprawl by increasing excise taxes on gasoline, all else fixed. In fact, one of the study's empirical specifications directly examines this issue by using the change in state gasoline excise taxes from 1986 to 1990. The results show that every penny increase in the state gasoline tax in the late 1980s is associated with nearly a five square-mile reduction in the size of an average urbanized area.

\section{Suggestions For Future Research}

A natural extension of this study is the investigation of the relationship between gasoline prices (gasoline excise taxes) and urbanized areas over time, as opposed to one point in time. In this manner, one can determine the extent to which the rate of increase of urban sprawl has been affected by market swings in the price of gasoline that have occurred, especially since the 1970s. Further, this would allow a longer span of time to analyze how changes in policy regarding state gasoline excise taxes have impacted the rate of growth of land into urbanized areas.

\section{Endnotes}

* Thanks to David Clark and John Marcis for comments on an earlier draft. All remaining errors are the responsibility of the author.

1. This section, particularly the description of the monocentric model, draws heavily from Brueckner and Fansler (1983) and Mills and Hamilton (1984). 
2. Technically, their model explains the distance from the urban center to the urban-rural boundary, which can be interpreted as the size of the urban area measured in square miles, for example.

3. Inter-area variation in the price of other goods is dismissed by assuming that the price of other goods equals one. Also, most researchers, including Brueckner and Fansler (1983), assume that the inter-area variation in the rental price of capital used in the production of housing is small, therefore, can be eliminated from the list of variables in the profit-maximizing conditions.

4. The following discussion implies the model is one of a closed city. If the city is open and migration is costless, city size is related to income, urban fringe land prices and commuting cost. The closed city model implicitly assumes that labor market frictions such as job immobility restrict migration between urban areas, and a specific urban area $=\mathrm{s}$ utility is not a function of shocks from outside the area.

5. The data for the dependent variable, the amount of square miles of urbanized area in the state, will not be available for the 2000 Census until late 2003.

6. The authors, to get a more accurate measure of agricultural land near urban areas, justified their restricted sample. They also show that while the theoretical model shows how factors such as population, income and commuting costs impact the distance from the city center to the rural-urban boundary, the static results implied by the theory also hold for the total land area of the city. The urbanized area definition represents this total land area.

7. Alternatively, the sum of all land in the state inside urban areas was used as the dependent variable, controlling for the number of urban areas in each state on the right-hand side. The results using that specification are generally consistent to those reported in this study.

8. In the linear model, while the estimated coefficients of the variables are similar as those for Equation (2), significance levels change in two cases. Income and the price of gasoline are statistically significant and traditional significance levels, while the population variable is estimated to have insignificant impacts on the dependent variable. A RESET test of the linear model also finds that specification to be adequate. A log linear specification (all variables taken as natural logs except TRANSIT) yields results consistent with those for Equation (2), including the fact the estimated coefficients for $\ln ($ PGASTOT) and TRANSIT are statistically insignificant. A notable difference between the log linear specification and that of Equation (2) is that the RESET test shows that the former is NOT an adequate specification (Chi-Square=8.15).

9. The linear specification of Equation (3) yields nearly equivalent results as those shown in Table 2. Again, the major difference is that in the linear specification, the coefficient on income is statistically insignificant while that of the gasoline price variable is estimated to have a negative and statistically significant impact on urban size.

10. The estimated coefficients of LANDP and LANDP^2 indicate that the price at which the impact of land prices on urban size switches from negative to positive is approximately $\$ 2700$. Four states, CT, NJ, MA and RI had a value of LANDP that exceeded that amount in 1990. Only four other states had values of LANDP that exceeded $\$ 2000$ (DE, FL, MD, NH).

11. Of course, the costs to the rest of the state=s economy must be analyzed to determine if increasing such a tax brings a net benefit.

12. Having the excise tax variable in first-difference form also is a step at examining how a longer-term change in commuting costs impacts urban sprawl. Building new residential, commercial or industrial structures that tend to increase the size of urban areas can generally be considered a long-run decision, thus changes in commuter costs over time, rather than the level of costs at one time, should tend to have a larger impact on that behavior.

\section{References}

1. Breslaw, J.A., "Density and Urban Sprawl: Comment", Land Economics, Vol. 66, No. 4, pp. 464-68, 1990.

2. Brueckner, J.K. and Fansler, D.A., "The Economics of Urban Sprawl: Theory and Evidence on the Spatial Size of Cities", The Review of Economics and Statistics, Vol. 65, No. 3, pp. 479-82, 1982.

3. Mills, E.S., Urban Economics, Glenview, IL: Scott Foresman, 1972.

4. Mills, E.S. and Hamilton, B.W., Urban Economics, $3^{\text {rd }}$ Edition, Glenview, IL: Scott Foresman, 1984.

5. $\quad$ Muth, R.F., Cities and Housing, Chicago: University of Chicago Press, 1969. 
6. Ohls, J.C. and Pines, D., "Discontinuous Urban Development and Economic Efficiency”, Land Economics, Vol. 51, No. 3, pp. 224-34, 1975.

7. Peiser, R.B., "Density and Urban Sprawl", Land Economics, Vol. 65, No. 3, pp.193-204, 1989.

8. Ramsey, J.B., "Tests for Specification Errors in Classical Linear Least-Squares Analysis", Journal of the Royal Statistical Association, Series B, Vol. 71, pp. 350-71, 1969.

9. Wheaton, W.C., "A Comparative Static Analysis of Urban Spatial Structure", Journal of Economic Theory, Vol. 9, pp. 223-37, 1974.

10. White, H.A., "A Heteroskedasticity-Consistent Covariance Matrix Estimator and a Direct Test for Heteroskedasticity", Econometrica, Vol. 48, pp. 817-838, 1980.

11. Williams, D.C., Urban Sprawl, Santa Barbara, CA: ABC-CLIO, Inc., 2000.

Notes 
Notes 


\section{Do Not Print This Page!!!}

\section{Endnotes}

"Thanks to David Clark and John Marcis for comments on an earlier draft. All remaining errors are the responsibility of the author.

${ }^{1}$ This section, particularly the description of the monocentric model, draws heavily from Brueckner and Fansler (1983) and Mills and Hamilton (1984).

${ }^{2}$ Technically, their model explains the distance from the urban center to the urban-rural boundary, which can be interpreted as the size of the urban area measured in square miles, for example.

${ }^{3}$ Inter-area variation in the price of other goods is dismissed by assuming that the price of other goods equals one. Also, most researchers, including Brueckner and Fansler (1983), assume that the interarea variation in the rental price of capital used in the production of housing is small, therefore, can be eliminated from the list of variables in the profit-maximizing conditions.

${ }^{4}$ The following discussion implies the model is one of a closed city. If the city is open and migration is costless, city size is related to income, urban fringe land prices and commuting cost. The closed city model implicitly assumes that labor market frictions such as job immobility restrict migration between urban areas, and a specific urban area $=\mathrm{s}$ utility is not a function of shocks from outside the area.

${ }^{5}$ The data for the dependent variable, the amount of square miles of urbanized area in the state, will not be available for the 2000 Census until late 2003.

${ }^{6}$ The authors, to get a more accurate measure of agricultural land near urban areas, justified their restricted sample. They also show that while the theoretical model shows how factors such as population, income and commuting costs impact the distance from the city center to the rural-urban boundary, the static results implied by the theory also hold for the total land area of the city. The urbanized area definition represents this total land area.

${ }^{7}$ Alternatively, the sum of all land in the state inside urban areas was used as the dependent variable, controlling for the number of urban areas in each state on the right-hand side. The results using that specification are generally consistent to those reported in this study.

${ }^{8}$ In the linear model, while the estimated coefficients of the variables are similar as those for Equation (2), significance levels change in two cases. Income and the price of gasoline are statistically significant and traditional significance levels, while the population variable is estimated to have insignificant impacts on the dependent variable. A RESET test of the linear model also finds that specification to be adequate. A log linear specification (all variables taken as natural logs except TRANSIT) yields results consistent with those for Equation (2), including the fact the estimated coefficients for $\ln$ (PGASTOT) and TRANSIT are statistically insignificant. A notable difference between the log linear specification and that of Equation (2) is that the RESET test shows that the former is NOT an adequate specification (ChiSquare $=8.15$ ). 
${ }^{9}$ The linear specification of Equation (3) yields nearly equivalent results as those shown in Table 2. Again, the major difference is that in the linear specification, the coefficient on income is statistically insignificant while that of the gasoline price variable is estimated to have a negative and statistically significant impact on urban size.

${ }^{10}$ The estimated coefficients of LANDP and LANDP^2 indicate that the price at which the impact of land prices on urban size switches from negative to positive is approximately $\$ 2700$. Four states, CT, NJ, MA and RI had a value of LANDP that exceeded that amount in 1990. Only four other states had values of LANDP that exceeded \$2000 (DE, FL, MD, NH).

${ }^{11}$ Of course, the costs to the rest of the state=s economy must be analyzed to determine if increasing such a tax brings a net benefit.

${ }^{12}$ Having the excise tax variable in first-difference form also is a step at examining how a longerterm change in commuting costs impacts urban sprawl. Building new residential, commercial or industrial structures that tend to increase the size of urban areas can generally be considered a long-run decision, thus changes in commuter costs over time, rather than the level of costs at one time, should tend to have a larger impact on that behavior.

\section{REFERENCES}

Breslaw, J.A., "Density and Urban Sprawl: Comment”, Land Economics, Vol. 66, No. 4, pp. 464-68, 1990.

Brueckner, J.K. and Fansler, D.A., "The Economics of Urban Sprawl: Theory and Evidence on the Spatial Size of Cities", The Review of Economics and Statistics, Vol. 65, No. 3, pp. 479-82, 1982.

Mills, E.S., Urban Economics, Glenview, IL: Scott Foresman, 1972.

Mills, E.S. and Hamilton, B.W., Urban Economics, $3^{\text {rd }}$ Edition, Glenview, IL: Scott Foresman, 1984.

Muth, R.F., Cities and Housing, Chicago: University of Chicago Press, 1969.

Ohls, J.C. and Pines, D., "Discontinuous Urban Development and Economic Efficiency", Land Economics, Vol. 51, No. 3, pp. 224-34, 1975.

Peiser, R.B., "Density and Urban Sprawl”, Land Economics, Vol. 65, No. 3, pp.193-204, 1989.

Ramsey, J.B., "Tests for Specification Errors in Classical Linear Least-Squares Analysis", Journal of the Royal Statistical Association, Series B, Vol. 71, pp. 350-71, 1969.

Wheaton, W.C., "A Comparative Static Analysis of Urban Spatial Structure", Journal of Economic Theory, Vol. 9, pp. 223-37, 1974.

White, H.A., "A Heteroskedasticity-Consistent Covariance Matrix Estimator and a Direct Test for Heteroskedasticity", Econometrica, Vol. 48, pp. 817-838, 1980. 
Williams, D.C., Urban Sprawl, Santa Barbara, CA: ABC-CLIO, Inc., 2000. 